\title{
Student as a Personality: Dynamics of Associative Criteria
}

\author{
Alsu Ashrapova, Sholpan Zharkynbekova, Ludmila Svirina, Maria Loginova
}

\begin{abstract}
This paper is devoted to the study of a student's linguistic personality from the standpoint of the theory of linguistic-cultural types. The relevance of the study is due to the actively developing anthropological linguistics field of the theory of linguocultural type, within the framework of which generalized recognizable personalities as representatives of a certain linguistic culture are considered. The object under study is the conceptual characteristics and the resulting reactions to the stimulus word "student". The purpose of this work is to linguistically represent a student as a person, to describe the notional component of the typified personality concept based on associative attributes. The paper proposes to expand the conceptual space of a character type by means of the associations obtained and to consider the character type of "student" as a person who is beyond the bounds of a cliche. The character type of student is a vivid representative of the sociocultural group, embodying the educational values of society. According to our observations, the description of the linguocultural character type of student through the eyes of students themselves gives a more detailed representation of the substantive component of the concept. The study is based on the associative and semantic field "student" which includes linguistic units reflecting the lexical-semantic space of student life; associated with the mental, emotional, physical, material, intellectual condition of a student; denoting character traits representing specific concepts / specific objects of the material world (educational supplies, a kind of instant food, etc.), etc.

Keywords: association, associative field, concept, linguistic and cultural character type, conceptual component.
\end{abstract}

\section{INTRODUCTION}

In any modern society, at all stages of its development, one can meet a recognizable, generalized personality type, in whose interests to get an education, become a specialist, form the basis of the intelligentsia, embodying the spiritual values of a thinking collective. We attribute to this type of personality the linguistic and cultural character type of "student". It is customary to understand linguistic and cultural character type "a typified personality, a representative of a certain social group recognizable by the specific characteristics of verbal and non-verbal behaviour and deduced value orientation" $[1: 13]$. By its research nature, a character type refers to the concept of a typified personality which consists of three components: conceptual, figurative, and value (according to V.I. Karasik). [2-7] Currently, there are a large number of studies on modelling of a character type in various linguistic cultures. A methodology for the description of linguocultural character types has been developed. According to our data, students were not

Revised Manuscript Received on November 08, 2019.

* Correspondence Author

Alsu Ashrapova, Kazan Federal University

Sholpan Zharkynbekova, Gumilyov Eurasian National University

Ludmila Svirina, Kazan Federal University

Maria Loginova, Gumilyov Eurasian National University considered from the position of typicality in linguistic scientific literature.

\section{METHODS}

In this study, we used a definitional analysis, an interpretive method, and an associative experiment as an additional and complementary method for describing the content of the "student" concept.

To study the conceptual component of the type, dictionary entries were analysed. According to explanatory and etymological dictionaries, encyclopedias, a student word has a unique definition: "a learner in a higher educational institution (university, institute, conservatory, and academy)". Latin word "Student" comes from the present participle studiÕ - "I work hard", "I study diligently", "I try." According to the definitions, the status of a student is indicated, the destination is marked. To describe a student as a person and to objectively represent the image in question, a free associative experiment was conducted in which students from four higher educational institutions took part (Eurasian National University named after L.N. Gumilyov, Kazakh University of Technology and Business, Eurasian Humanitarian Institute, Astana Medical University) of different faculties and their corresponding specialties, the range of respondents is from 1 to 4 courses, Russian-speaking people, despite the language of education (Kazakh, Russian, multilingual group).

\section{RESULTS AND DISCUSSION}

Linguocultural character type is a concept of a typified personality, and the concept, according to G.G. Slyshkin and V.I. Karasik, "is grouped around a certain "strong" (that is, value-accentuated) point of consciousness from which associative vectors diverge. The associations that are most relevant for native speakers comprise a core of the concept, while less significant associations are the periphery. The concept has no clear boundaries; as we move away from the core, a gradual attenuation of associations occurs. A linguistic or speech unit with which the "central point" of the concept is actualized serves as the name of the concept". [8, 77] One of the defining indicators is a group of noun words that reflect the semantic proximity of the concept in question and form its core [9].

The most common associations for students are associated with an educational institution (university / uni $(+16)$, higher school $(+2)$, institute $(+2))$, because it is impossible to imagine a student outside a university as a place where one can get an education. During the formation of their special knowledge and professional competencies, 
important moments for students are related to the organization of the educational process $($ study $(+11)$, lecture $(+5)$, classes $(+2)$, platonus) and the place of its implementation (audience $(+2))$, is represented by different types of knowledge control (session (+5), exam (+4), high-stakes testing (+4), abstract $(+4))$, transmitted by the traditional attributes of student life as its symbol (a mark book). Associations reflecting the sincere intention, purpose, for which the student came to study, are represented by abstract and specific nouns: education (+3), knowledge (+4), diploma (+3), scholarship $(+7)$, grant $(+3)$, dormitory / hostel $(+10)$. Representation associated with certain images embodying wisdom, knowledge, experience (professor), search, information (applicant), aspiration (bachelor).

The following groups of words combined on the basis of an analysis of the reactions received and our observations, allow us to consider a student as a person with his inherent characteristics, communicative behaviour and value attitudes.

Consider a group of words - nominations with which students positions themselves: activist (+2), hard worker, work like a beaver, work like a horse, glad-hander, loafer, athlete, mask shows, friends (+4), person, ordinary person over the age of 17 up to 22 years old. The allegorical representation of the student in the image of a beaver and a horse is compared with the main function of a student and a beaver and a horse, the purpose of which is to work hardly. The well-known expressions "to work like a beaver" or "to work like a horse", meaning "tirelessly and patiently working person" [10], can be identified with the etymology of the word "student" - lat. "I work hard, work diligently, try." Ambivalent nominations are "hard worker" and "loafer" as the fact of the presence of two categories of people in student society. Perhaps the sincerity, openness and easy naivety of students can be correlated with the expressive expression of a glad-hander, meaning "a disinterested, open-minded, simple and unsophisticated person"[11]. Neutral designations are "a person, an ordinary person aged 17 to 22 years, an athlete, and friends".

Among the associations for the "student" stimulus, a group of abstract nouns was singled out, indicating character traits: responsibility $(+6)$, determination $(+2)$, curiosity, independence $(+3)$, ambition. It is worth noting the positive marking of lexemes, which create a pleasant image of a student with a goal, plans, character that is responsible for the tasks and seeks to solve them independently.

A large group of reaction words are abstract nouns related to the student's mental, emotional, physical, material, intellectual condition: freedom / will (+9), youth / juvenility $(+7)$, dream, aspiration (+2), goal, development, enthusiasm $(+2)$, energy, movement, perspective, opportunity, activity $(+2)$, positive, adventures (+3), joy / fun $(+4)$, luck, choice, dating, partying, party / get-together / hangouts (+4), survival, saving, moonlighting, insomnia, hunger (+6), depression, discontent, longing / sadness, freebie, lack of sleep $(+2)$, sleep $(+4)$.

From the position of the conceptual component, the universal concept-regulator "freedom" [12: 20-21] can be represented by another name of the concept "wish". For students, freedom and wish are synonymous and are perceived as "the ability to do what you want, to do as you wish" [12: 55]. For many students entering an educational institution, the status of a student is related to independence: make decisions independently, do not report to parents, do not ask permission and do not ask for questions, and do not be under daily control. As an addition, the results of the study [13] can be used, in which informants under the age of 25 years participated (in our opinion, the main part could be students). According to the survey, young people (probably students) "mean the stimulus word "freedom" by independence from anyone; "I do what I want"; complete freedom of action; "own master"; left to oneself"; no one bothers, "walk, have fun" [13]. The respondents calling the reaction "freedom / will" to the stimulus word "student", are guided by own personal life experience or the imaginary world, real / unrealistic ideas. "Freedom and free will" enter the associative field, which is "not only a fragment of a person's memory (knowledge), a fragment of a system of semantic and grammatical relationships, but a fragment of images of consciousness, motives and ratings" [12: 98]. Being motivated by the fulfilling their cherished dreams, achieving their goals, striving to grow, taking advantage of opportunities, prospects, and developing personal qualities, students, as a rule, try to realize them at the appropriate age - it's time for youth / juvenility. Energy, activity, movement, enthusiasm, positive are the key moments in the students' life, which makes them special. Many young people perceive student life as an adventure with intellectual, emotional content. An indicator of a student's emotional state is joy as "one of the fundamental human emotions, an integral component of spiritual culture" [14:18]. Different joyful moments can be accompanied by excitement, can be a reaction to luck or serve as the basis for fun.

The student society is made up of different young people with a different attitude to the educational process: insomnia, lack of sleep, sleep are associated with careful preparation for classes, with a great desire to study theoretical material, broaden their horizons, use the acquired special knowledge in practice, read additional educational literature; for some, training is a freebie (khaliava), i.e. somehow, carelessly, for free, for nothing [15,23].

Some informants believe that the image of a student is inextricably linked with poverty, therefore, with hunger, saving, and part-time work. Students correlate freedom / will with liberty and financial independence, thereby proving to themselves and their parents, to those around them that they, as persons, are able to solve any issues, including material ones, by themselves. The previously considered concept of "poverty" in the youth linguistic consciousness allowed researchers to draw a number of conclusions, one of which is "poverty implies an acute need for food" [16,22]. Perhaps this is why students have parties, hangouts, events of an entertaining nature, meetings for informal communication, where there are a minimum of costs and a maximum of impressions.

Particular reactions in the associative field are "longing / sadness, survival". The motives and estimates which are hidden behind these lexemes make it possible to interpret differently what the informants had in mind because of their personal experience and the bygone. The concept of "longing" is a bunch of emotive meanings, the content of which is "languor, melancholy, sadness, boredom, despondency, spleen, anxiety, homesickness, regret for the lost, longing for something that has not happened yet, longing for loved ones, to close people" $[17,20,21]$. The listed 
meanings of "longing" describe the state of a student at different stages of his/her student life. At a certain moment, disappointment sets in, awareness of loneliness leads to a state of depression, uselessness. The significance of oneself as an individual occupies a student on a par with the educational process. The search for the meaning of life, oneself, one's place, role, meaning, affirmation and self-determination leads to internal "survival". Therefore, the proposed "survival" reaction can be associated not only with material wealth, money, the possession of a car, expensive equipment, the ability to dress fashionably and be among the elite part of the student community (golden youth).

Among the associations noted there were verbs that mainly reflected actions (actionality): learn / teach $(+2)$, get know, grow, dress, work, and sleep (+2), miss, complain, write off. We can distinguish the most "specific" of them (to learn, teach, cheat off, skip, complain), general (to learn, grow, dress, work, sleep). Since the main activity of a student is connected with the educational process, and not with additional actions of part-time work, participation in events, etc., the verbal reaction "learn and teach" to the "student" stimulus word is obvious. Only students have the opportunity to "skip", pupils diligently go to classes, graduates go to work. During study, students are relatively free, and have the right to skip classes; if one is not satisfied with the quality of educational services, teaching methods, and living conditions - he/she have the opportunity to "complain".

The subject designations of a student, there symbolic representation is expressed by a group of nouns that designate specific concepts / specific objects of the material world: notebooks, bag, A4 paper, books, battery, doshirak, rollerton, food $(+2)$, money. Judging by the subject symbolism, a student's personality is determined by three indicators of his/her lifestyle. First of all, a student is a trainee, and is actively involved in this process (notebooks, bags, A4 paper, books, a battery), secondly, healthy nutrition (more precisely, its absence) and, in general, food occupy a special place, thirdly, money (their availability or unavailability) is a necessary component of a student life.

In addition to the group of words-nominations, we have identified a group of words denoting a sign that characterizes a student. The resulting adjective reactions have an ambiguous opinion: on the one hand, negative characteristics that create an unpleasant image of a student: miserable, nervous, drunk, beggar, hungry, poor (+3), sleepy; on the other hand, adjectives with a positive connotation characterizing the best qualities of a student: successful, young, promising everywhere

\section{SUMMARY}

As the analysis of associations showed, 153 reactions were given to the only student stimulus word, excluding repetitive ones. The reactions obtained entered the associative field of the "student" concept and made it possible to include additional characteristics in the substantial nature of the type under consideration.

\section{CONCLUSIONS}

The linguistic understanding of the character type "student" allows us to consider it as a person which is beyond the bounds of a cliche. According to the associative experiment, the reactions obtained to the stimulus word "student", on the one hand, describe and supplement the substantive component of the concept, and on the other hand, expand the idea of a student as a person with a set of certain value settings [18].

The substantive content boils down to a modest set of constitutive attributes: 1) the learner; 2) a higher and secondary specialized educational institution [19]. The associative understanding of the substantive component of the concept "student" is broader and is represented by different categories of words (abstract and specific nouns, adjectives that indicate quality and attribute, action verbs, free phrases). Complementing the definitional space of the "student", and interpreting the reactions obtained, one can expand the stereotypical idea of a student as a person with an intellectual base and the necessary value systems in modern society.

\section{ACKNOWLEDGEMENTS}

The work is performed according to the Russian Government Program of Competitive Growth of Kazan Federal University.

\section{REFERENCES}

1. Karasik V.I. Language circle: personality, concepts, discourse Volgograd: Peremena, 2002.447 p.33

2. Regina F. Frey, Angela Fink, Michael J. Cahill, Mark A. McDaniel, Erin D. Solomon. Peer-Led Team Learning in General Chemistry I: Interactions with Identity, Academic Preparation, and a Course-Based Intervention. Journal of Chemical Education 2018, 95 (12)

3. Douglas J. Simpson John Dewey's Concept of the Studentanadian Journal of Education / Revue canadienne de l'éducation Vol. 26, No. 2 pp. 183-200, 2001

4. Shaiakhmetova L., Shayakhmetova L., Mukhametzyanova L.The Way Concept In The Author's Picture Of The World (By Example Of The Story A Warn Path By Eudora Welty)//Modern Journal Of Language Teaching Methods.Vol.7, Is.9. - P.652-656. 2017

5. Boydston, J. A. The school and society. Carbondale, IL: Southern Illinois University Press.1980

6. Burnett, J. R.. Preface. In J. A. Boydston, (Ed.) The school and society Carbondale, IL: Southern Illinois University Press. 1980

7. Shao-Liang Zheng, Michael G. Campbell. Connecting Key Concepts with Student Experience: Introducing Small-Molecule Crystallography to Chemistry Undergraduates Using a Flexible Laboratory Module. Journal of Chemical Education, 95 (12), 2018

8. Karasik V.I., Slyshkin G.G. Linguocultural concept as a unit of research / V.I. Karasik, G.G. Slyshkin // Methodological problems of cognitive linguistics. Voronezh: Voronezh State University, 2001. Pp. $75-80$

9. Shamsutdinov R., Mukharlyamova L., Zharkynbekova Sh., Ashrapova A. Semantic Field of 'Wish / Desire 'in the Tatar Language // Tarih Kultur Ve Sanat Arastirmalari Dergisi-Journal of History Culture And Art Research.Vol.6, Is.6. - P.117-124. 2017

10. Mokienko V.M. From everyday meaning to an artistic image // Bulletin of the Kemerovo State University.2016. Number 3. P. 164-169

11. Phraseological Dictionary of the Russian Literary Language / Edited by A.I. Fedorova.M.: Astrel AST, 2008. 880 p.

12. Solokhina A.S. The concept of "freedom" in the English and Russian linguistic cultures: a thesis for the degree of candidate of philosophical sciences. Volgograd, 2004.189 p.

13. Zhanpeisova N.M., Zhumakhanova A.Zh. The concept of "freedom" in the English, Russian and Kazakh linguistic cultures // Science: yesterday, today, tomorrow: a collection of papers based on the materials of the XIII international scientific and practical conference. No. 6 (13).Novosibirsk: Sibak, 2014

14. Sayko O.A. Joy // Anthology of concepts. Edited by V.I. Karasik, I.A Sternin. Vol. 7. Volgograd: Paradigm, 2009. Pp. 18-34 
15. Ozhegov S.I. and Shvedova N.Yu. Explanatory Dictionary of the Russian Language: 80,000 words and phraseological expressions / Russian Academy of Sciences. V.V. Vinogradov Russian Language Institute. 4th edition, amended. M.: LLC "A TEMP", 2006. 944 p.

16. Steshina E.G. Wealth and poverty // Anthology of concepts. Edited by V.I. Karasik, I.A. Sternin. Vol. 7 Volgograd: Paradigm, 2009. Pp. 138-154

17. Dimitrova E.V. Longing // Anthology of concepts. Edited by V.I. Karasik, I.A. Sternin. Vol. 1. Volgograd: Paradigm, 2005. Pp. 268-273

18. R. R. Zamaletdinov, F. H. Gabdrakhmanova, G. F. Zamaletdinova. The Language Nomination And The Turkic Conceptual System (On The Material Of The Tatar Language). Herald NAMSCA 3, 2018. pp. 896-898.

19. Kuznetsova A. A., Svirina L. O., Iliasova L. G., Relevant Topics Motivating Learners Of English To Produce Meaningful Utterances//Ad Alta-Journal Of Interdisciplinary Research. Vol.8, Is.1. - P.203-205. 2018

20. Sadeghpour, F., Far, M. G., Khah, A. R., \& Akbardokht Amiri, M. A. Marketing Strategic Planning and Choosing the Right Strategy using AHP Technique (Case Study: Ghavamin Bank Mazandaran). Dutch Journal of Finance and Management, 1(2), 45. (2017). https://doi.org/10.29333/djfm/5821

21. Oliveira, F. K. D., Oliveira, M. B. D., Gomes, A. S., \& Queiros, L. M. Identifying User Profiles from Statistical Grouping Methods. Journal of Information Systems Engineering \& Management, 3(1), 06. (2018).

22. Alkhateeb, M. Multiple Representations in 8th Grade Mathematics Textbook and the Extent to which Teachers Implement Them. International Electronic Journal of Mathematics Education, 14(1), 137-145. (2019). https://doi.org/10.12973/iejme/3982

23. Shatilova, L. M., Borisova, V. V., \& Kasatkina, O. A. Representation of the linguistic and cultural concept "lie" in the French and Russian language picture of the world. Opción, 34(85-2), 257-276. (2018). 